\title{
光氧化还原催化下以肜的衍生物作为前体亚胺自由基的产生及其反应
}

\author{
宋常华 $a, b$ 沈 许 ${ }^{b}$ 于 芳 ${ }^{a}$ 何宇鹏 $*, a$ 俞寿云*,$b$ \\ ( ${ }^{a}$ 辽宁石油化工大学化学化工与环境学部 辽宁抚顺 113001) \\ ( ${ }^{b}$ 南京大学化学化工学院 生命分析化学国家重点实验室 南京 210023)
}

\begin{abstract}
摘要 在可见光氧化还原催化的条件下, 从肟的衍生物( $O$-酰基朊、 $O$-芳基肟和 $\alpha$-亚胺氧杂酸等)出发, 高效清洁地产生 了亚胺自由基. 这方法促进了亚胺自由基反应活性的系统研究. 亚胺自由基主要有以下 4 种反应模式: (1)对芳烃的加成 反应, (2)分子内的氢迁移, (3)对烯烃的加成反应, (4) Norrish-I 型断裂 $(\alpha$-位的碳-碳键断裂)反应. 综述了近几年来在光氧 化还原催化的条件下，以肟的衍生物作为前体，亚胺自由基的产生及其参与的典型反应.
\end{abstract}

关键词 氮自由基; 亚胺自由基; 光氧化还原催化; 可见光

\section{Generation and Application of Iminyl Radicals from Oxime Derivatives Enabled by Visible Light Photoredox Catalysis}

\author{
Song, Changhua ${ }^{a, b} \quad$ Shen, $\mathrm{Xu}^{b} \quad$ Yu, Fang ${ }^{a} \quad$ He, Yupeng ${ }^{*, a} \quad$ Yu, Shouyun ${ }^{*, b}$ \\ ( ${ }^{a}$ College of Chemistry, Chemical Engineering and Environmental Engineering, \\ Liaoning Shihua University, Fushun, Liaoning 113001) \\ $\left({ }^{b}\right.$ State Key Laboratory of Analytical Chemistry for Life Science, School of Chemistry and \\ Chemical Engineering, Nanjing University, Nanjing 210023)
}

\begin{abstract}
The advent of visible light photoredox catalysis has transformed the way of single-electron transfer (SET) processes and accessing radical species. As a result, the chemistry of nitrogen-centered radicals has witnessed a remarkable gain in interest. Specifically, under visible light photoredox catalysis, iminyl radicals can be generated from oxime derivatives, such as $O$-acyl oximes, $O$-aryl oximes and $\alpha$-imino-oxy acids. Meanwhile, the reactivity of iminyl radcials is investigated systematically. Iminyl radicals can undergo four major classes of reactions, namely addition to arenes, intramolecular hydrogen atom transfer and subsequent reactions, addition to alkenes, Norrish type-I fragmentation (cleavage of $\alpha$-carbon-carbon bonds) and subsequent reactions. In this review, the most significant progresses in the use of oximes and their derivatives as iminyl precursors are discussed and their engagement in photoredox-mediated transformations is outlined.
\end{abstract}

Keywords nitrogen-centered radical; iminyl radical; photoredox catalysis; visible light

含氮化合物被广泛应用于药物、农药、食品添加剂 和含能材料中 ${ }^{[1]}$. 基于含氮化合物的重要性, 开发构建 碳-氮 $(\mathrm{C}-\mathrm{N})$ 键的方法非常重要, 而且化学家们越来越 多地关注于提高 $\mathrm{C}-\mathrm{N}$ 键的构建效率、选择性和可持续 性. $\mathrm{C}-\mathrm{N}$ 键的构建已经取得了很多进展, 经典的 $\mathrm{C}-\mathrm{N}$ 键的构建大都利用氮原子的亲核性. 最近基于氮自由基 $\mathrm{C}-\mathrm{N}$ 键的构建方法作为传统离子型反应的补充开始引 起人们的关注 ${ }^{[2]}$. 然而, 缺乏产生氮自由基的可靠高效
清洁的方法，极大地制约了氮自由基化学的发展. 可见 光氧化还原催化介导的自由基型反应，因环境友好、条 件温和以及反应易处理等优点, 受到化学家们的青睐 ${ }^{[3]}$. 利用可见光氧化还原催化技术可以高效地产生氮自由 基，使得氮自由基化学得到很大的发展. 目前氮自由基 化学的研究也成为有机合成领域的一个热点, 特别是在 光氧化还原催化方面 ${ }^{[4]}$.

亚胺自由基(iminyl radical)是经典的氮自由基主要

\footnotetext{
* Corresponding authors. E-mail: yushouyun@nju.edu.cn; yupeng.he@1npu.edu.cn Received April 6, 2020; revised April 29, 2020; published online May 7, 2020 Dedicated to the 40th anniversary of Chinese Journal of Organic Chemistry. Project supported by the National Natural Science Foundation of China (Nos. 21732003, 21978124) and the Innovative Talent Project of Educational Department of Liaoning Province (No. LR2018019).

国家自然科学基金(Nos. 21732003, 21978124)和辽宁省省教育厅高等学校创新人才(No. LR2018019)资助项目.
} 
类型之一(还包括酰胺自由基、胺基自由基及其铵正离 子自由基等), 由于其分子内存在 $\mathrm{C}\left(\mathrm{sp}^{2}\right)-\mathrm{N}$ 键, 属于 $\sigma$ 型自由基, 既有亲电性也有亲核性 ${ }^{[5]}$. 肜的衍生物由于 分子内存在较弱的 $\mathrm{N}-\mathrm{O}$ 键 $(\mathrm{BDE} \approx 209 \mathrm{~kJ} / \mathrm{mol})^{[6]}$, 成为 产生亚胺自由基的优良前体. 目前研究较多的主要有三 类肟衍生物: (1) $O$-酰基肟衍生物, (2) $O$-芳基肟衍生物 和(3) $\alpha$-亚胺氧杂酸 ( $\alpha$-imino-oxy acid) 衍生物(Scheme 1). 前两类肟的衍生物可以在可见光氧化还原催化条件下 被激发态的光敏剂还原产生亚胺自由基, 第三类肜的衍 生物可以被激发态的光敏剂氧化产生亚胺自由基. 亚胺 自由基参与的反应模式主要有以下四种: (1)对芳烃的加 成反应; (2)分子内的氢原子迁移及后继反应; (3)对烯烃 的加成反应; (4) Norrish-I 型断裂 ( $\alpha$-位的 C-C 键断裂) 及后继反应(Scheme 1). 本文主要总结了近几年来在光 氧化还原催化的条件下, 以䏡的衍生物作为前体, 亚胺 自由基的产生及其参与的典型反应.

\section{1 对芳烃的加成反应}

2015 年, 我们课题组 ${ }^{[7]}$ 利用可见光氧化还原催化技 术, 从 $O$-酰基的肜 1 高效清洁地产生亚胺自由基. 该自 由基随后对芳烃进行分子内加成, 发生分子内亚胺化, 制备了一系列的含氮杂芳环 2 , 包括吡啶、喹啉和菲啶 等(Scheme 2a). 该反应利用 $O$-酰基的肜与激发态光敏 剂的单电子转移来还原断裂 $\mathrm{N}-\mathrm{O}$ 键, 从而生成亚胺自 由基(Scheme 2b). 由于 $O$-酰基的引入增加了底物的氧 化性和离去基团的离去性能, 所以是该策略取得成功的 关键原因. 为了进一步提高反应效率, 制备了新试剂 $O$ 苯甲酰基羟胺(BHA), 该试剂可以在布朗斯特酸帮助下 与醛 3 原位生成 $O$-酰基的朊, 再在光氧化还原催化条件 下发生分子内的亚胺自由基对芳烃的加成反应. 从醛出
发, “一锅法” 合成含氮芳杂环 $4^{[8]}$ (Scheme 2c). 2017 年, 我们 ${ }^{[9]}$ 又报道了一种以 $O-2,4-$ 二硝基苯肜醚 $\mathbf{5}$ 为原料, 在没有光催化剂存在的情况下使用可见光照射, 同样可 以合成菲啶和喹啉类化合物 $\mathbf{6}($ Scheme $2 \mathrm{~d})$. 该反应是借 助 $O-2,4-$ 二硝基苯肟醚和 $\mathrm{Et}_{3} \mathrm{~N}$ 形成电子给体受体(EDA) 复合物介导的电子转移实现的.

2016 年, 谢红旗和程辟课题组 ${ }^{[10]}$ 开发了一种无金 属可见光氧化还原催化 $O-2,4-$ 二硝基苯氧肜醚分子 7 的 环化反应(Scheme 2e). 该策略使用的有机染料型光催化 剂 $\operatorname{eosin} \mathrm{Y}$ 相较于 $\mathrm{Ru}$ 或 Ir 配合物光敏剂, 价格便宜, 反 应条件简单、温和, 环保. Akita 与 Koike 等 ${ }^{[1]}$ 报道了由 $N$-(2-芳基芳基氨基)吡啶盐 9 选择性合成取代菲啶类化 合物的方法(Scheme 2f). 该方法中, 光激发中间体 11 中 的吡啶基从末端芳基处获得一个电子, 生成关键的自由 基中间体, 具有较高三重态能量的光催化剂, 在前体的 能量传递中也起着至关重要的作用.

\section{2 分子内的氢原子迁移反应}

$\mathrm{C}\left(\mathrm{sp}^{3}\right)$ - $\mathrm{H}$ 直接官能团化是有机化学领域极具挑战 性的课题, 其经典解决方案之一是 Hofmann-LöfflerFreytag 反应(HLF 反应), 反应的关键步骤是分子内的 1,5-氢原子迁移(HAT). HLF 反应的发现已经超过一百 年, 该反应还有一些明显的缺点, 比如, 反应条件非常 苛刻, 经典的 HLF 反应通常需要在强酸性介质中, 紫外 光解(或者加热)胺的氯化物产生氮自由基; HLF 反应通 常实现远程 $\mathrm{C}\left(\mathrm{sp}^{3}\right)-\mathrm{H}$ 的卤化或者分子内的胺化, 其他 类型的官能团化难以引入, 特别是远程 $\mathrm{C}-\mathrm{C}$ 键的构建 非常具有挑战性.

2015 年, 我们 ${ }^{[12 a]}$ 使用可见光促进的光氧化还原催 化技术, 利用 $N$-氯磺酰胺作为酰胺自由基前体, 通过酰

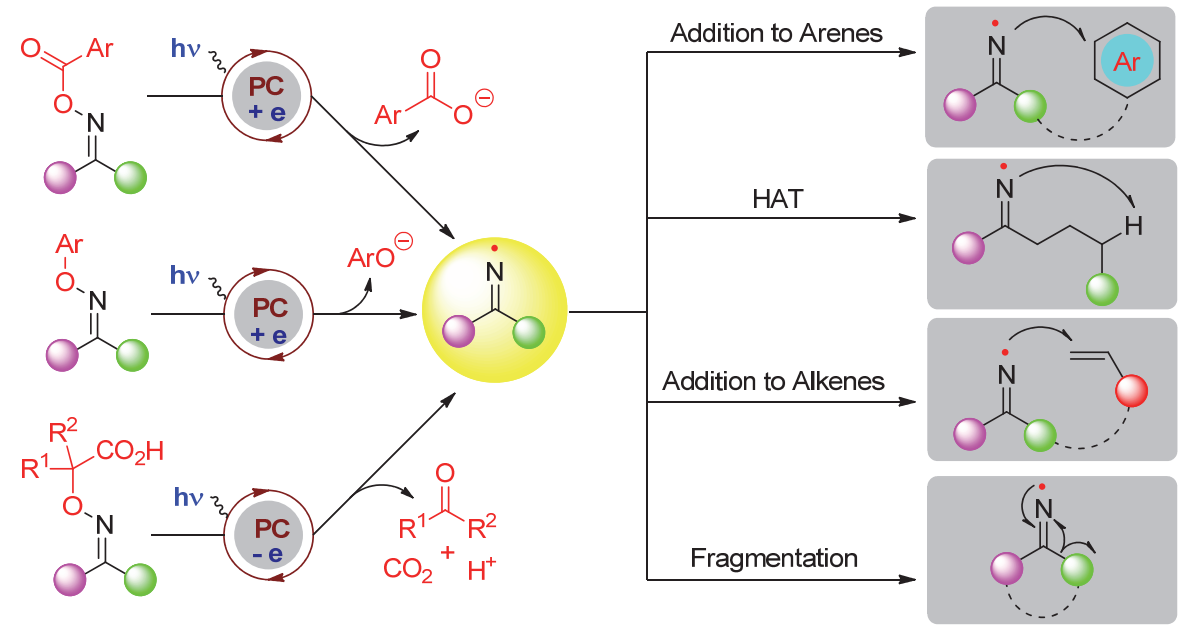

图式 1 光氧化还原催化的亚胺自由基的主要生成方法和反应模式

Scheme 1 Generation and reaction modes of iminyl radicals under photoredox catalysis 
(a) Yu's work<smiles>[R]c1ccccc1-c1ccccc1</smiles>

fac-lr(ppy $)_{3}(1 \mathrm{~mol} \%)$

$\mathrm{Ar}=4-\mathrm{F}_{3} \mathrm{CC}_{6} \mathrm{H}_{4}$

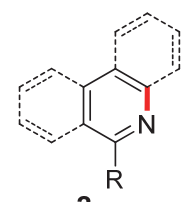

2

(c) Yu's work

(d) Yu's work

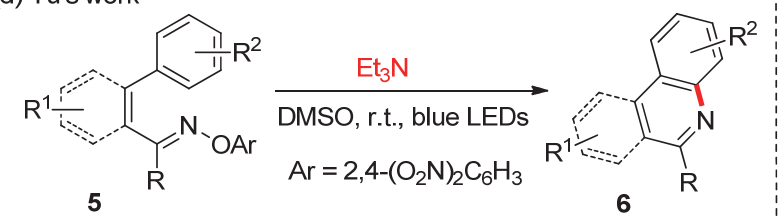<smiles>[R]c1cnc2c(c1[R])C=C[R1]C=C2</smiles><smiles>[R]C(=O)ON=C([R])c1ccccc1-c1ccccc1</smiles>
EDA complex<smiles>[R]C(=N)c1ccccc1-c1ccccc1</smiles>

(e) Xie's work<smiles>[R][R]1cccc(-c2ccccc2/C=N\Oc2cccc([N+](=O)[O-])c2)c1</smiles>

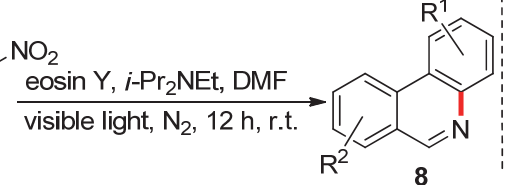

(b) Proposed mechanism

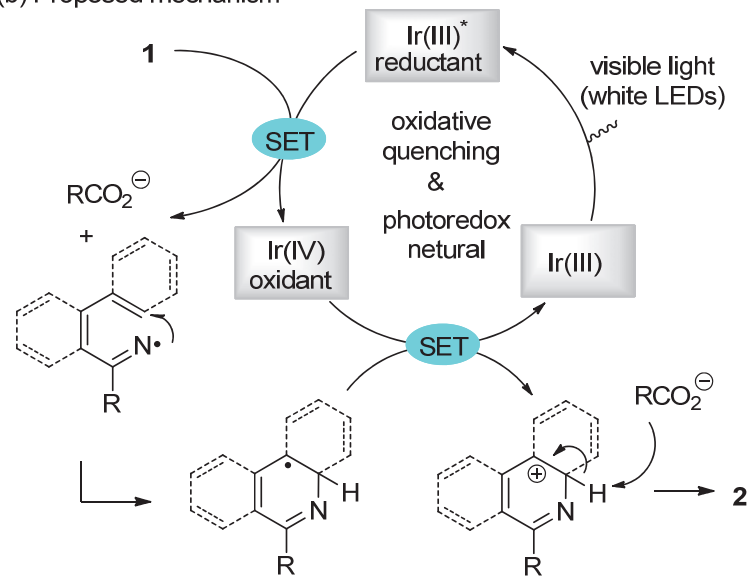

(f) Akita's work

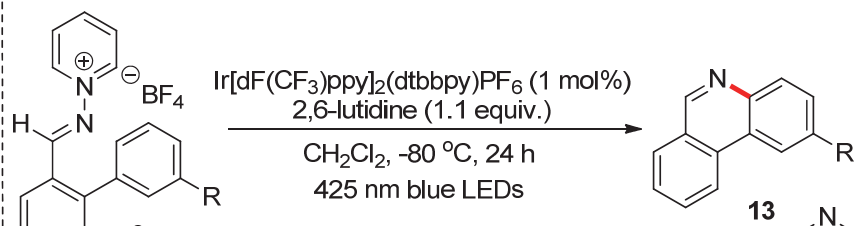

9
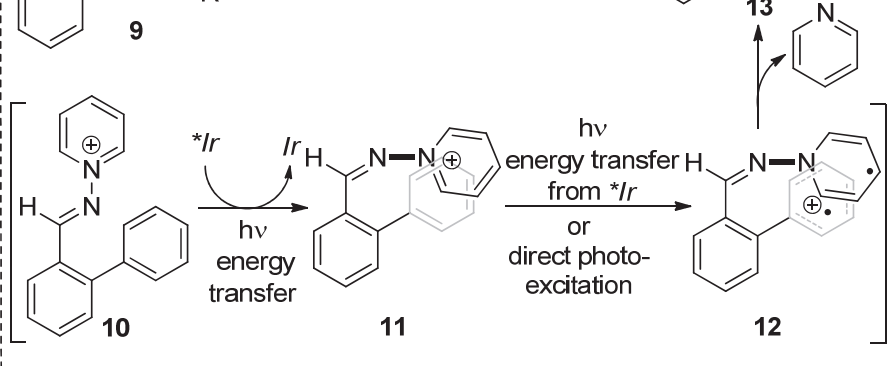

图式 2 可见光促进的亚胺自由基对芳基的加成反应

Scheme 2 Visible light-promoted addition of iminyl radicals to arenes

胺自由基的 1,5-HAT 过程, 成功地在近中性的条件下实 现了远程 $\mathrm{C}\left(\mathrm{sp}^{3}\right)-\mathrm{H}$ 的氯化和分子内酰胺化反应. 该方 案首次使用光氧化还原催化技术解决远程 $\mathrm{C}\left(\mathrm{sp}^{3}\right)-\mathrm{H}$ 官 能团化问题, 避免了经典 HLF 反应的强酸性和紫外光 照射等苛刻条件. 在这一工作的激发下, 我们 ${ }^{[12 b]}$ 进一 步通过亚胺自由基的 1,5-HAT 过程实现了 $\mathrm{C}\left(\mathrm{sp}^{3}\right)-\mathrm{H}$ 官 能团化. 使用 $O$-酰基肜衍生物 14 作为亚胺自由基前体, 在光氧化还原的条件下产生亚胺自由基, 发生 1,5-HAT 过程, 远程 $\mathrm{C}\left(\mathrm{sp}^{3}\right)-\mathrm{H}$ 使用烯基硼酸 15 作为碳自由基捕 获剂, 实现了远程 $\mathrm{C}\left(\mathrm{sp}^{3}\right)-\mathrm{H}$ 烯基化, 将经典的 HLF 反 应拓展到 $\mathrm{C}-\mathrm{C}$ 键构建领域(Scheme 3).

2017 年, Nevado 等 ${ }^{[13]}$ 同样使用 $O$-酰基肟衍生物 17 作为亚胺自由基前体, 在可见光氧化还原催化的条件 下, 利用 1,5-HAT 过程实现了分子内的 $\mathrm{C}\left(\mathrm{sp}^{3}\right)-\mathrm{H}$ 芳基 化和亚胺化反应(Scheme 4). 当使用醋酸作为添加剂时, 1,5-HAT 发生分子内芳基化, 生成苯并环己酮衍生物 18. 当反应加入碱(DABCO)时, 1,5-HAT 发生分子内亚胺化,

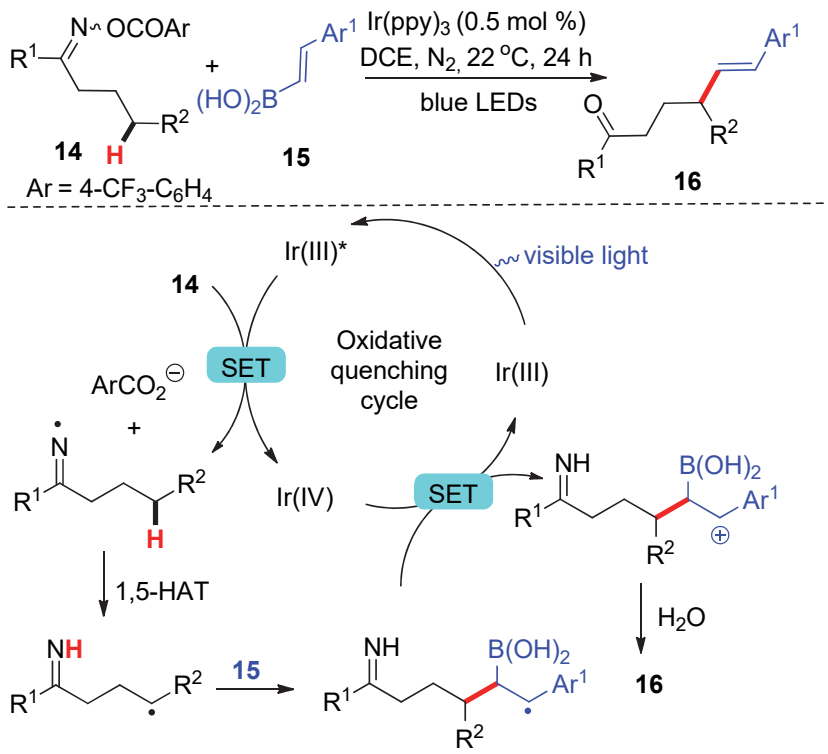

图式 3 远程 $\mathrm{C}\left(\mathrm{sp}^{3}\right)-\mathrm{H}$ 烯基化反应

Scheme 3 Remote $\mathrm{C}\left(\mathrm{sp}^{3}\right)-\mathrm{H}$ vinylation 


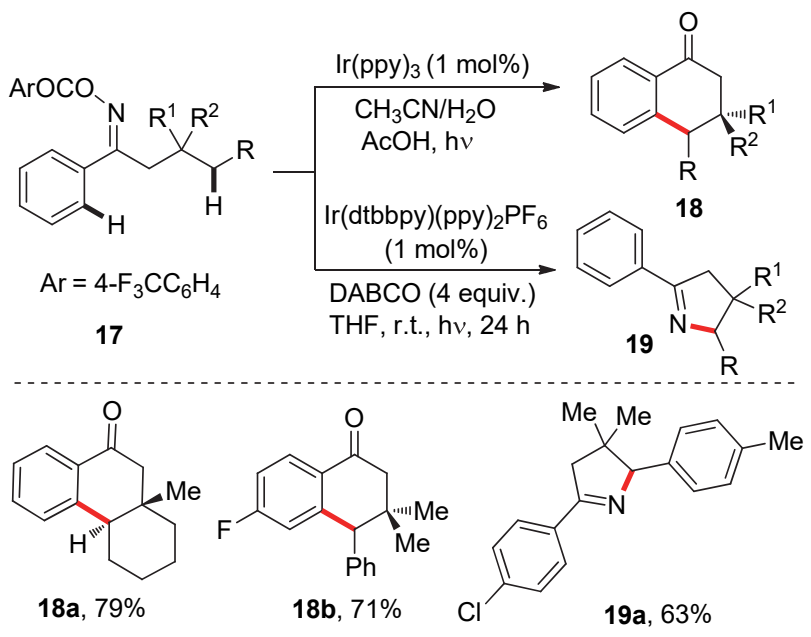

图式 4 分子内 $\mathrm{C}\left(\mathrm{sp}^{3}\right)$ - $\mathrm{H}$ 芳基化和亚胺基化反应 Scheme 4 Intramolecular $\mathrm{C}\left(\mathrm{sp}^{3}\right)-\mathrm{H}$ arylation and iminylation 构建 $\mathrm{C}-\mathrm{N}$ 键, 生成 $2 H$-吡咯类化合物 19.

2018 年, 段新华等 ${ }^{[14]}$ 也使 $O$-酰基肟衍生物 20 作为 亚胺自由基前体, 在可见光氧化还原催化的条件下, 利 用 1,5-HAT 过程, 使用苯乙烯衍生物 21 作为碳自由基的 捕获剂, 分别实现了远程 $\mathrm{C}\left(\mathrm{sp}^{3}\right)-\mathrm{H}$ 烷基化和烯基化 (Scheme 5). 他们发现反应的溶剂和添加剂对反应的结 果至关重要, 当反应加入水时, 烷基自由基被氧化为碳 正离子后，被水捕获，得到远程羟基烷基化产物 22 (Scheme 5a). 各种醇(甲醇, 乙醇和异丙醇等)也作为亲 核试剂捕获碳正离子, 获得相应的醚化产物. 2019 年, 他们课题组 ${ }^{[15]}$ 在此基础上实现了烯基化反应. 用同样 的苯乙烯衍生物作为碳自由基受体, 将反应溶剂改为二 甲基亚砜(DMSO), 并用布朗斯特酸作为添加剂, 得到 相应远程烯基化产物 23 (Scheme 5b).

2017 年, Leonori 等 ${ }^{[16]}$ 采用 $\alpha$-亚胺氧杂酸衍生物 24 作为亚胺自由基前体, 实现了一系列远程 $\mathrm{C}\left(\mathrm{sp}^{3}\right)-\mathrm{H}$ 卤 化和叠氮化反应(Scheme 6a). 与 $O$-酰基肟通过氧化淬 灭激发态的光敏剂产生亚胺自由基不同， $\alpha$-亚胺氧杂酸 是通过还原淬灭激发态的光敏剂产生亚胺自由基. 结果 表明该反应有广泛的底物适应性, 并且同样适用于天然 产物的后期修饰. 几乎同时, Studer 等 ${ }^{[17]}$ 利用 $\alpha$-亚胺氧 杂酸衍生物 27 作为亚胺自由基前体, Michael 受体 28 作 为碳自由基捕获剂, 以类似的策略实现了酮远程 $\gamma$-位烷 基化反应(Scheme 6b).

随后, 利用亚胺自由基 1,5-HAT 的策略实现 $\mathrm{C}-\mathrm{N}$ 、 $\mathrm{C}-\mathrm{S}$ 以及 $\mathrm{N}-\mathrm{S}$ 键的构建也得到发展. 付华 ${ }^{[18]}$ 与吴劼 ${ }^{[19]}$ 课题组先后报道了简单实用的可见光促进的亚胺自由 基介导的分子内 $\mathrm{C}-\mathrm{H}$ 活化串联环化反应和分子间插 $\mathrm{SO}_{2}$ 反应. 两种反应只需要可见光照射, 不需要额外添 加催化剂、氧化剂、酸和碱. 以上反应是借助 $O-2,4-$ 二 硝基苯肟醚与胺或 $\mathrm{DABCO} \cdot\left(\mathrm{SO}_{2}\right)_{2}$ 形成 $\mathrm{EDA}$ 复合物,
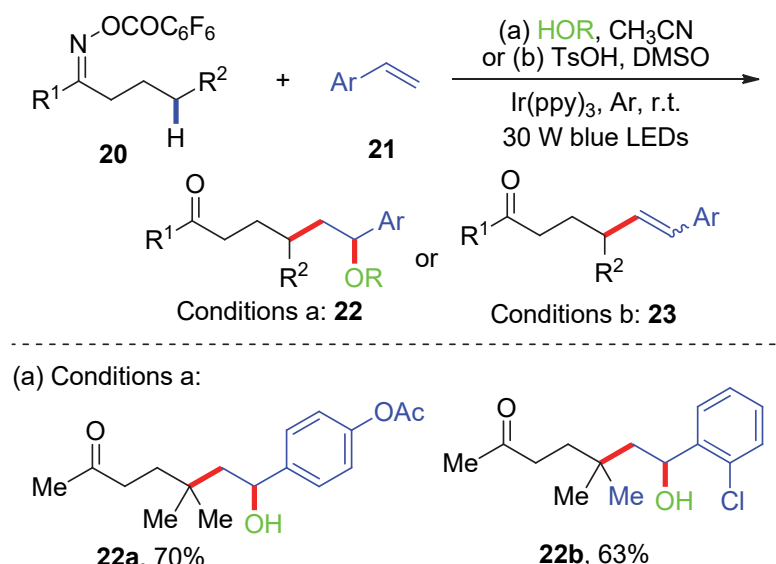

22a, $70 \%$

22b, $63 \%$

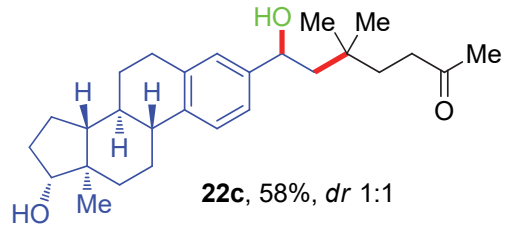

(b) Conditions b:<smiles>COc1ccc(C=CC(C)(C)CCC(C)=O)cc1</smiles>

23a, $66 \%, E / Z=3: 4$<smiles>CC(=O)CCC(C)(C)C=Cc1cccc(Br)c1</smiles><smiles>CC(=O)CCC(C)(C)C=C(c1ccccc1)c1ccccc1</smiles>

23c, $72 \%$

23b, $40 \%, E / Z=8: 1$

图式 5 远程 $\mathrm{C}\left(\mathrm{sp}^{3}\right)-\mathrm{H}$ 烷基化和烯基化反应

Scheme 5 Remote $\mathrm{C}\left(\mathrm{sp}^{3}\right)-\mathrm{H}$ alkylation and vinylation

(a) Leonori's work

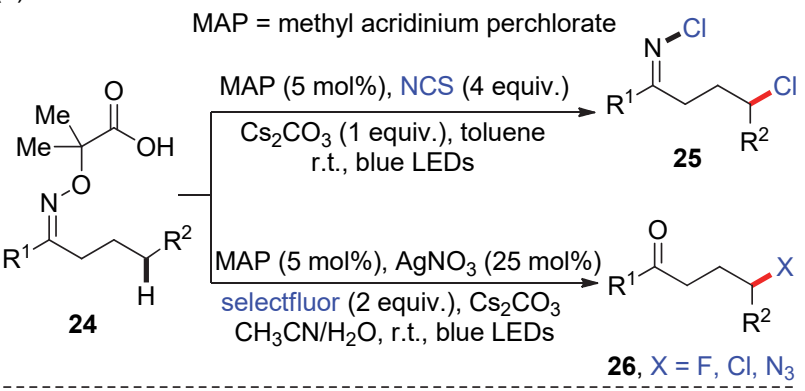

(b) Studer's work

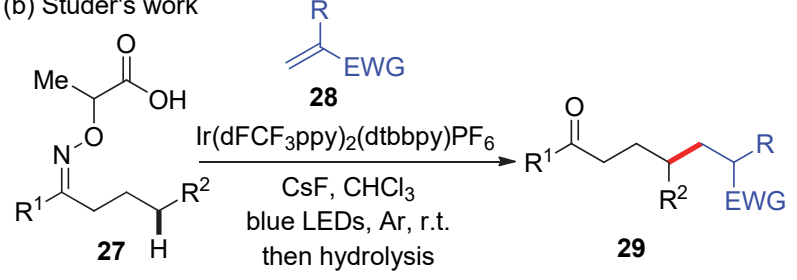

图式 $6 \alpha$-亚胺氧杂酸衍生物的远程 $\mathrm{C}\left(\mathrm{sp}^{3}\right)-\mathrm{H}$ 官能团化 Scheme 6 Remote $\mathrm{C}\left(\mathrm{sp}^{3}\right)-\mathrm{H}$ functionalization from $\alpha$-iminooxy acids

随后 $\mathrm{N}-\mathrm{O}$ 键断裂生成亚胺自由基，再进行后续反应实 现咪唑 31 以及噻嗪类衍生物 34 的合成(Scheme 7). 
(a) Fu's work<smiles>[R]C([R])N([R])C/C([Al])=N/[O]</smiles><smiles>[R]c1nc([Bi])cn1[R2]</smiles><smiles>N#Cc1cccc(-c2cn3c(n2)CCCC3)c1</smiles>

31 a $75 \%$<smiles>O=[W][Mg]</smiles><smiles>COc1ccc(-c2cn3c(n2)CCCC3)cc1</smiles>

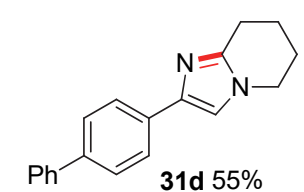

(b) Wu's work

$$
\text { (b) }
$$

图式 7 EDA 复合物介导的远程 $\mathrm{C}\left(\mathrm{sp}^{3}\right)-\mathrm{H}$ 官能团化反应

Scheme 7 EDA complex-mediated remote $\mathrm{C}\left(\mathrm{sp}^{3}\right)-\mathrm{H}$ functionalization

\section{3 对烯烃的加成反应}

亚胺自由基对烯烃的加成环化反应是构建含氮杂 环类化合物的重要方法之一. 早在 1997 年, Zard 和 Newcomb 等 ${ }^{[20]}$ 发现, 酮腙的衍生物 35 在 $\mathrm{Bu}_{3} \mathrm{SnH}$ 的作 用下，能够发生 $\mathrm{N}-\mathrm{N}$ 键均裂产生亚胺自由基 36, 随后 亚胺自由基对 $\mathrm{C}=\mathrm{C}$ 双键进行分子内加成, 发生 5-exotrig 环化反应, 最后㩲取氢原子得到产物 37 (Scheme 8 a). 随后他们发现在镍粉作为还原剂的条件下, $O$-乙酰 基肪 38 被单电子还原产生亚胺自由基, 该自由基发生 环化形成的碳自由基有三种不同的反应途径: (1)㩲取氢 原子得到产物 39, (2) 被氧化成碳正离子后消除得到烯烃 40, (3)被氧化成碳正离子后被醋酸捕获得到醋酸酯 41 $\left(\right.$ Scheme 8b) ${ }^{[21]}$.

Narasaka 等 ${ }^{[22]}$ 发现在紫外光激发下，1,5-二甲氧基 䒬(DMN)与 $O$-芳基肜醚衍生物发生单电子转移, 形成 亚胺自由基, 对 $\mathrm{C}=\mathrm{C}$ 双键进行分子内加成后从 1,4-环 己烯中㩲取氢原子得到 $2 H$-吡咯类化合物 43 (Scheme 9). 这些早期的例子启发了可见光氧化还原催化的条件 下，亚胺自由基对烯烃加成反应的研究.

(a)

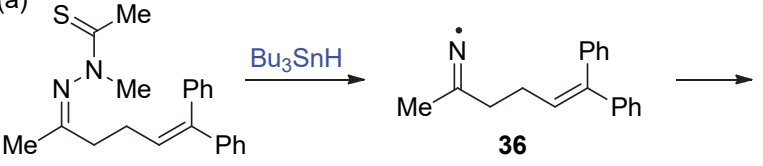

35<smiles>CC1=NC(C(c2ccccc2)c2ccccc2)CC1</smiles>

(b)
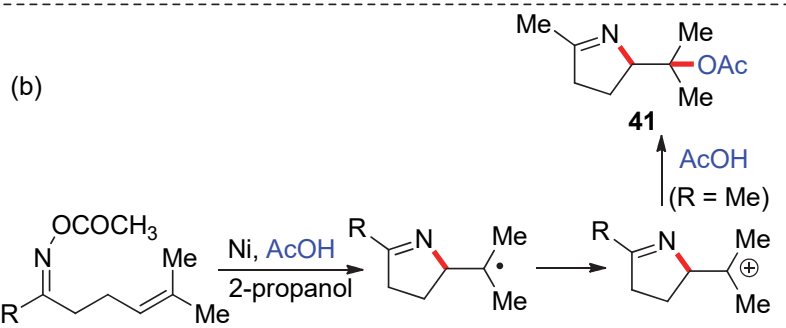

38, $\mathrm{R}=\mathrm{Me}$ or $\mathrm{Ph}$

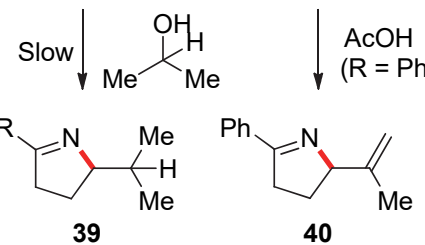

图式 $8 \mathrm{Bu}_{3} \mathrm{SnH}$ 介导的亚胺自由基对烯烃的分子内加成反应 Scheme $8 \quad \mathrm{Bu}_{3} \mathrm{SnH}$-mediated intramolecular addition of iminyl radicals to alkenes

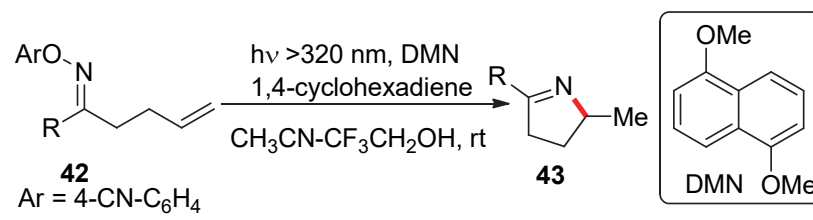

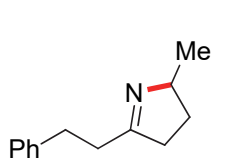

43a, $75 \%$<smiles>CCOC(=O)CC1CCC(CCc2ccccc2)=N1</smiles>

43d, $64 \%$<smiles>CC(C)C1CCC(CCc2ccccc2)N1</smiles>

43b, $78 \%$

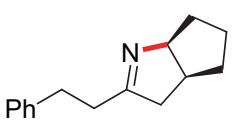

$43 e, 78 \%$<smiles>CCCCCCCCCCCCCCCCC</smiles>

43c, $75 \%$

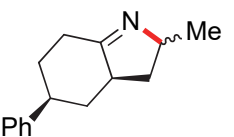

43f, $60 \%$
图式 9 紫外光诱导的亚胺自由基对烯烃的分子内加成反应 Scheme 9 UV-induced intramolecular addition of iminyl radicals to alkenes

2015 年, Leonori 等 ${ }^{[23]}$ 发现了可见光氧化还原催化 的条件下, $O$-芳基肜醚衍生物 $\mathbf{4 4}$ 可以氧化淬灭激发态的 光催化剂产生亚胺自由基, 对烯烃进行分子内加成, 最 后㩲取氢原子得到最终产物 45. 其反应途径如 Scheme 10 中 path a 所示, 反应始于肟醚 44 与激发态的光敏剂 的单电子转移, 产生亚胺自由基, 随后发生 5-exo-trig 环 化形成烷基自由基 $\mathbf{4 7}$, 自由基 47 从环己二烯中擭取一 


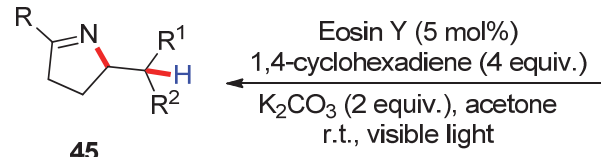<smiles>[R]/C(=C/CC/C([R])=N/[Al])CC</smiles>

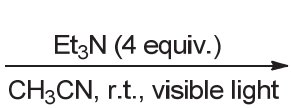<smiles>[R]C1=NC(C([R])([R])C)CC1</smiles>

path a

44, $\mathrm{Ar}=2,4-\left(\mathrm{O}_{2} \mathrm{~N}\right)_{2} \mathrm{C}_{6} \mathrm{H}_{3}$

path b

46

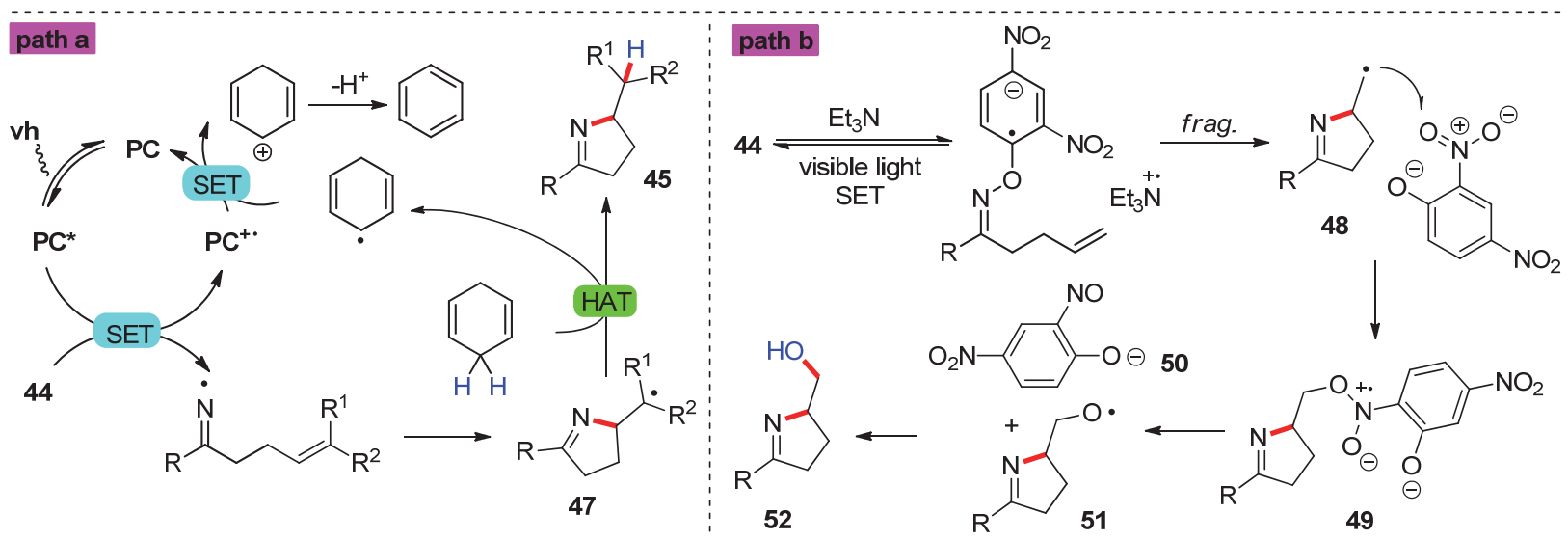

图式 10 可见光促进的亚胺自由基对烯烃的分子内加成反应环化氢化以及羟化反应

Scheme 10 Visible light-promoted intramolecular addition of iminyl radicals to alkenes

个氢原子得到产物 45. 同时, 他们还发现 $O$-芳基肟醚衍 生物 44 可以与三级胺形成 EDA 复合物, 该复合物可以 被可见光激发, 电子转移后, $O$-芳基肟醚发生碎片化, 生成亚胺自由基和 2,4-二硝基苯酚负离子. 该亚胺自由 基同样发生 5-exo-trig 环化. 与可见光氧化还原催化的 条件的后继反应不同, 环化产生的烷基自由基 48 没有 篗取氢原子, 而是被 2,4-二硝基苯酚负离子氧化成醇类 化合物 52(Scheme 10, path b).

2016 年, 冯超和 Loh 等 ${ }^{[24]}$ 报道一个亚胺自由基启 动的 $O$-酰基肟衍生物 53 与烯醇硅醚 54 的自由基串联反 应(Scheme 11). 与前面的反应类似, 亚胺自由基发生环 化后得到烷基自由基，该自由基进一步被烯醇硅醚 54 捕获, 最终得到高度官能团化的 $2 H$-吡咯衍生物 $\mathbf{5 5}$.

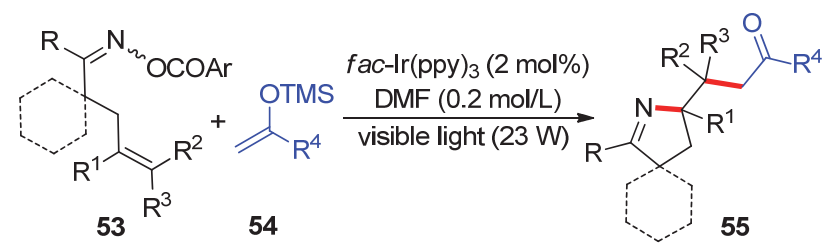

图式 11 可见光促进的亚胺自由基引发的串联反应 Scheme 11 Visible light-promoted and iminyl radical-initiated domino reactions

2017 年, Studer 和 Leonori 分别独立地发展了 $\alpha$-亚 胺氧杂酸衍生物 56 或者 58 作为亚胺自由基前体及其启 动的烯烃参与串联反应(Scheme 12). Studer 等 ${ }^{[25]}$ 使用缺 电子的烯烃作为烷基自由基的捕获剂, 得到烷基化的 2H-吡咯衍生物 57(Scheme 12a). Leonori 等 ${ }^{[26]}$ 使用类似 的策略, 考察了一系列烷基自由基的捕获剂, 一系列高
度官能团化的 $2 H$-吡咯衍生物 59, 包括卤化、硫三氟甲 基化、叠氮化、氰基化、烯基化、炔基化、胺化、硫化 等，产物的产率从中等到优良(Scheme 12b). 这些反应 都有一个问题没有解决，当产物有多个手性中心时，产 物的非对映选择性很不理想.

(a) Studer's work:

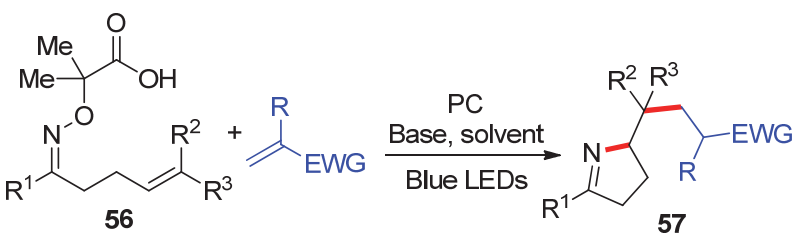

(b) Leonori's work:
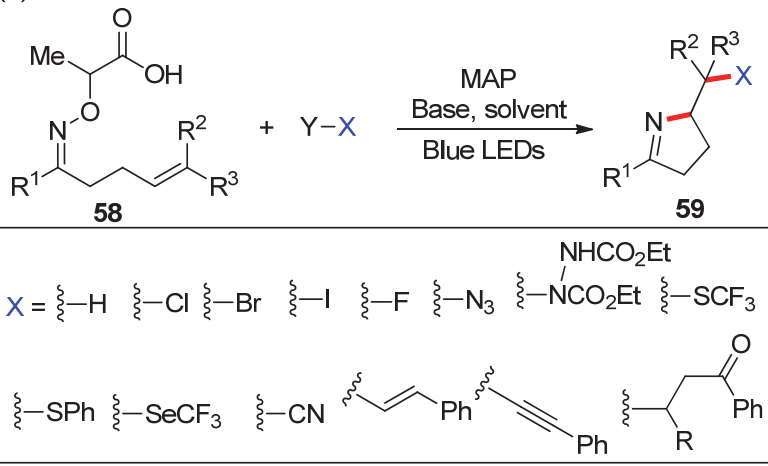

图式 $12 \alpha$-亚胺氧杂酸衍生物自由基串联反应

Scheme 12 Domino reactions of $\alpha$-imino-oxy acids

\section{Norrish-I 型断裂反应}

亚胺自由基的 Norrish-I 型断裂 $(\alpha$ 位的 $\mathrm{C}-\mathrm{C}$ 键断 裂)是由亚胺自由基产生其他自由基(特别是碳中心自由 基)的高效方法，伴随着生成一个稳定的氰基. 其中开 
环断裂反应为官能团化脂肪腈的合成提供了一种重要 的方法 ${ }^{[27]}$. 这一反应类型中, 研究最为充分的是环丁酮 衍生物的开环官能团化反应. 由于四元环的张力较大, 环丁酮衍生的亚胺或者肟的衍生物通过加热或光照发 生 $\mathrm{N}-\mathrm{X}$ 键 $(\mathrm{X}=\mathrm{O}, \mathrm{S}, \mathrm{N}$ 等)的断裂形成亚胺自由基, 发 生开环反应形成烷基自由基，该自由基可以进一步反应 引入不同的官能团. 这一领域的先驱者 Zard 等 ${ }^{[28]}$ 发现 $N$-颈荒基环丁酮亚胺 60 在 $\mathrm{Bu}_{3} \mathrm{SnH}$ 的促进下发生 $\mathrm{N}-\mathrm{S}$ 键均裂, 能够生成亚胺自由基 $\mathbf{6 1}$, 环张力导致亚胺自由 基的 $\alpha$ 位 $\mathrm{C}-\mathrm{C}$ 键断裂, 发生连续的开环反应, 生成烷 基自由基 62, 被缺电子的烯烃捕获后最终得到双环化 合物 63(Scheme 13).

由于可见光氧化还原催化条件的温和与高效性, 可 以兼容更多的烷基自由基的捕获剂, 实现更多类型的化 学转化. 最常用的烷基自由基的捕获剂为烯烃及其衍生 物. 2017 年, 肖文精和陈加荣等报道了一系列烯烃作为 烷基自由基捕获剂的工作. 他们报道可见光促进的环酮 肜酯 52 经历亚胺自由基开环后, 烷基自由基被芳基乙 烯类化合物捕获，实现了烯基化反应 ${ }^{[29]}$ 以及氧化烷基 化反应(Scheme 14a) ${ }^{[30]}$. 他们尝试了多种环酮肜酯, 包 括杂环、螺环、环张力较小环戊酮、环己酮以及樟脑衍 生物, 能够得到中等到优良的产率. 此种反应策略可以 将烯烃拓展为烯基叠氮、烯基腙等, 具有优良的底物适 应性.
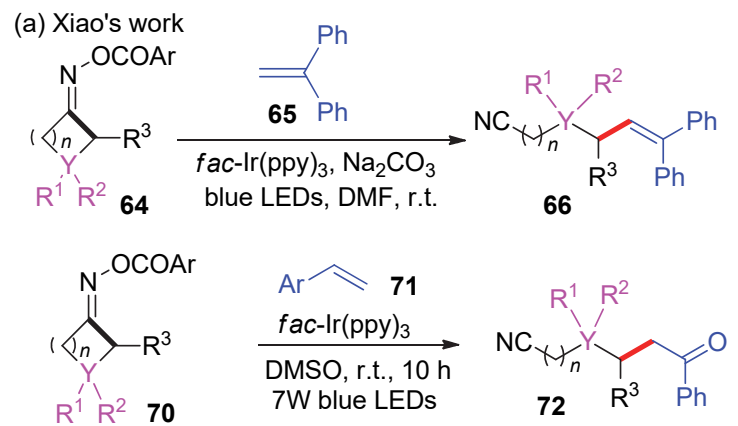

$\mathrm{Y}=\mathrm{C}, \mathrm{N}, \mathrm{O} ; n=1,2,3$

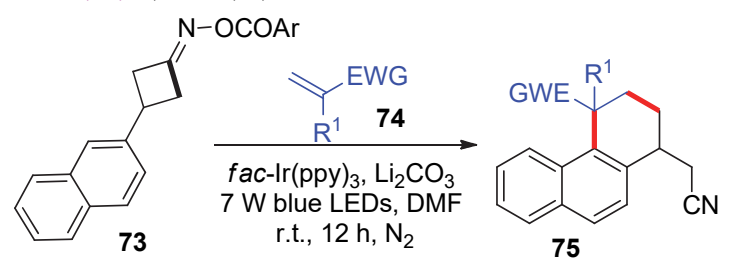

(b) Zhou's work

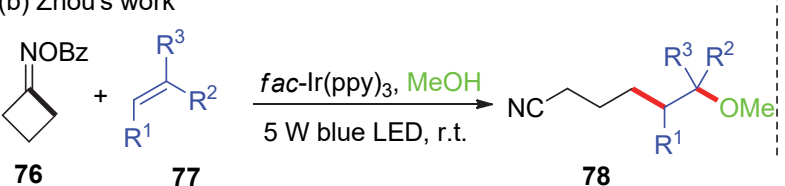

图式 14 可见光促进的环丁酮肜酯与烯烃的官能团化反应

Scheme 14 Visible light-promoted reactions of cyclobutanone oxime esters with alkenes

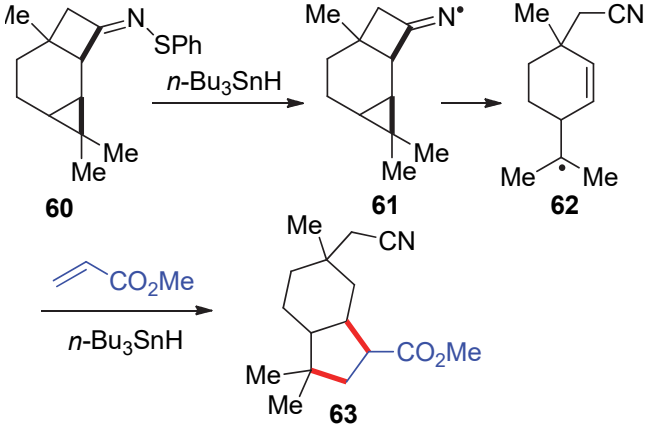

图式 $13 \mathrm{Bu}_{3} \mathrm{SnH}$ 介导的 $N$-颈苯基环丁酮亚胺开环反应 Scheme $13 \mathrm{Bu}_{3} \mathrm{SnH}$-mediated ring-opening of $\mathrm{N}$-mercaptophenyl cyclobutanones

随后，他们报道了 3 -芳基环丁酮肜酯 73 和缺电子 烯烃 74 的自由基加成/环化串联反应. 这种温和且氧化 还原中性的策略提供了一种高效实用的方法来获得各 种氰烷基化的 1,2,3,4-四氢菲产物 75, 具有良好的区域 选择性和产率 ${ }^{[31]}$. 周䂞等 ${ }^{[32]}$ 报道了可见光促进环丁酮 肜酯 76 与烯烃 77 和醇的三组分反应. 他们对环丁酮肜 酯、烯烃以及亲核试剂进行了研究，以中等到优良的产 率得到了一系列双官能团化反应(Scheme 14b). 我们课 题组 ${ }^{[12 b]}$ 也研究了环酮肟酯 67 开环官能团化反应 (Scheme 14c). 用烯基硼酸 68 作为烷基自由基的捕获剂, 实现了开环烯基化反应. 激发态的光敏剂被环丁酮肜酯 氧化淬灭，生成亚胺自由基，开环后得到烷基自由基，

(c) Yu's work

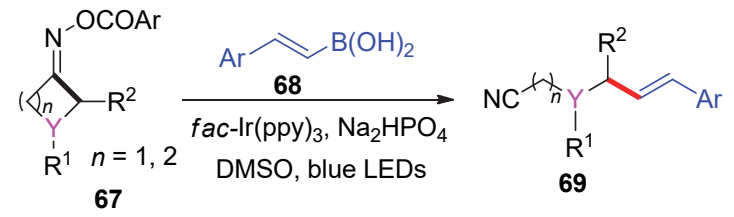

(d) Proposed mechanism

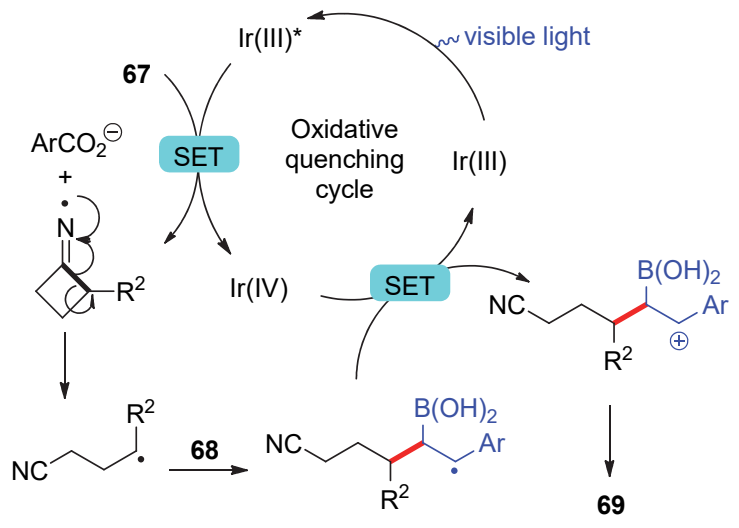


对烯基嗍酸进行加成, 形成的自由基中间体被高价态光 敏剂氧化成碳正离子，脱除硼酸后得到目标产物 69 (Scheme 14d).

Leonori 等 ${ }^{[16]}$ 报道了可见光促进的环戊酮肜羧酸衍 生物开环氟化反应(Scheme 15a). 他们采用还原淬灭的 方式从环戊酮肜羧酸衍生物 79 获得亚胺自由基, 开环 形成烷基自由基, 随后与亲电试剂氟化剂反应最终生成 氟化产物 80. 该反应的立体选择性不能很好地控制, 产 物的非对映选择性比较差. Waser 等 ${ }^{[33]}$ 使用炔基的高价 碘化合物 82 作为烷基自由基捕获剂，实现了开环炔基 化反应(Scheme 15b). 四元和五元环酮衍生的肜羧酸均 能有效裂解, 在温和的条件下以良好的收率得到含有炔 烃的腈类化合物 $\mathbf{8 3}$.

(a) Leonori's work
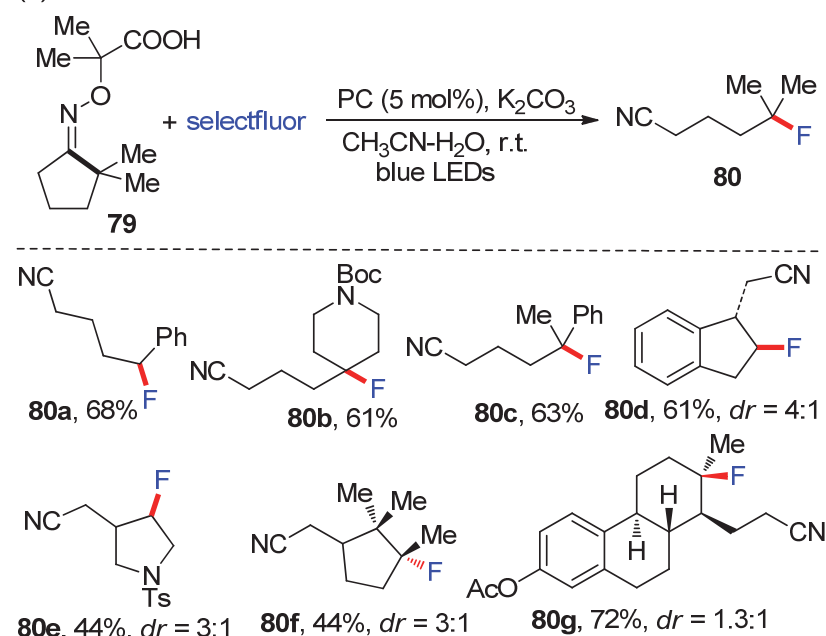

$\mathbf{8 0 e}, 44 \%, d r=3: 1 \quad \mathbf{8 0 f}, 44 \%, d r=3: 1 \quad \mathbf{8 0 g}, 72 \%, d r=1.3: 1$

(b) Waser's work

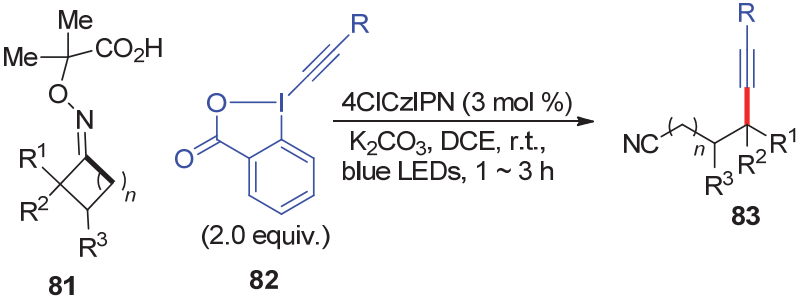

图式 15 环酮肟羧酸衍生物介导的远程氟化和炔基化反应

Scheme 15 Remote fluorination and alkynation of cycloketone oxime carboxylic acid derivatives

可见光促进的环酮肟酯经历亚胺自由基开环后烷 基自由基也可以进行 $\mathrm{SO}_{2}$ 插入反应，得到一系列氰基砜 类化合物(Scheme 16). 比如，吴劼和叶盛青等 ${ }^{[34]}$ 报道了 在光催化下, 通过亚胺自由基和二氧化硫的插入实现了 环酮肜酯的多组分磺酰化反应. 在可见光的照射下, $O-$ 酰基肟 84 被激发态的光催化剂还原产生亚胺自由基, 开环后得到烷基自由基，该自由基随后经历 $\mathrm{SO}_{2}$ 插入、 氧化单电子转移和亲核进攻等一系列转化生成官能团 丰富的 $\beta$-烷氧基(或者羟基)砜 87(Scheme 16a). 陆红健
等 ${ }^{[35}$ 报道了烯醇的三氟磺酸酯或者烯丙基三氟甲基砜 89 作为自由基受体和 $\mathrm{SO}_{2}$ 源, 无需外部加入 $\mathrm{SO}_{2}$, 构建 各类结构丰富多样的 $\beta$-酮砜和烯丙基砜 90 (Scheme $16 b)$. 唐课文等 ${ }^{[36]}$ 报道了使亚甲基环丙烷 92 作为自由 基受体，反应经历亚胺自由基的形成、 $\mathrm{C}-\mathrm{C}$ 键断裂、 $\mathrm{SO}_{2}$ 插入、对亚甲基环丙烷的加成、三元环开环和环化 等一系列过程，合成了 2-氰基磺化-3,4-二氢菜 93 (Scheme 16c).

(a) Wu's work

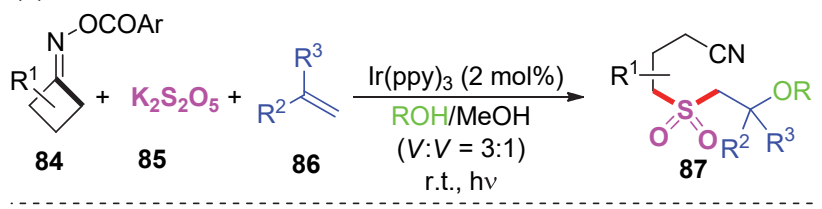

(b) Lu's work

(c) Tang's work

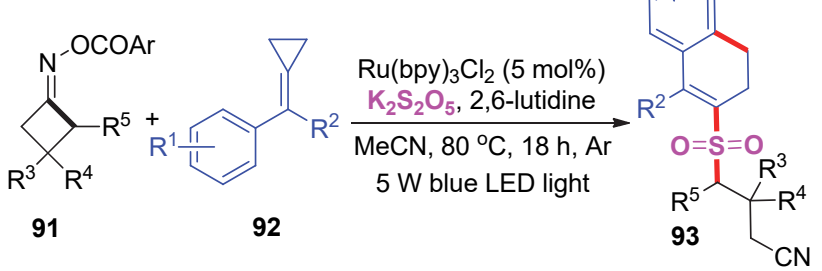

图式 16 环酮肟酯的开环和 $\mathrm{SO}_{2}$ 插入反应

Scheme 16 Ring-opening and $\mathrm{SO}_{2}$ insertion of cycloketone oxime ester

环酮肜酯开环后烷基自由基也可以被含氮杂芳环 捕获，实现 Minisci 类型的氮杂芳环的烷基化. 比如，夏 吾炣等 ${ }^{[37}$ 报道了可见光促进的 Minisci 型氮杂芳环氰烷 基化. 这种光化学方法为氰基取代杂芳烃的合成提供了 方便，对药物的开发具有一定的意义(Scheme 17).

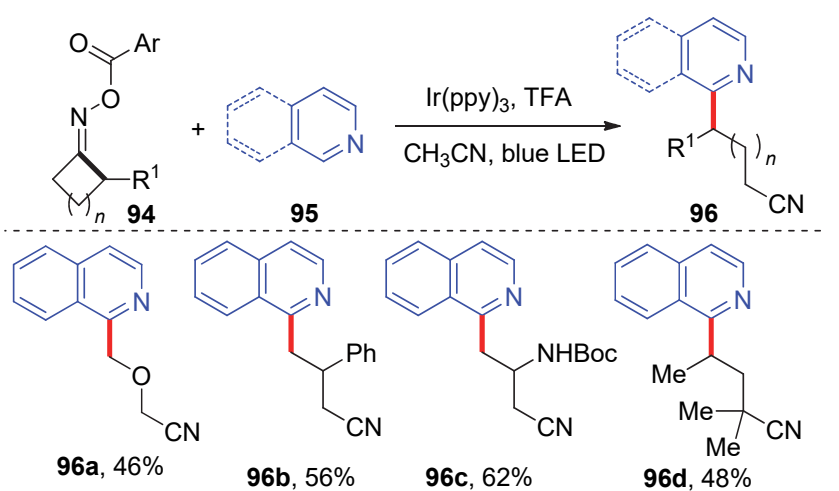

图式 17 环酮肜酯的开环和 Minisci 型反应

Scheme 17 Ring-opening and Minisci-type reaction of cycloketone oxime ester 
肖文精和陈加荣等 ${ }^{[38]}$ 使用有机染料作为光敏剂借 助分子间的 HAT 过程产生亚胺自由基. 该反应始于 $O$ 苠基肟醚 97 与激发态的光敏剂发生分子间的 HAT 过程, 生成的苄基自由基发生 $\beta$-断裂产生亚胺自由基, $\mathrm{C}-\mathrm{C}$ 键裂解形成的烷基自由基, 对烯烃 98 进行加成, 篗取氢 原子得到最后的产物 99 (Scheme 18). 这种通过 HAT 过 程产生亚胺自由基方法与通过电子转移产生亚胺自由 基的方法互为补充, 能够实现更多的化学转化.
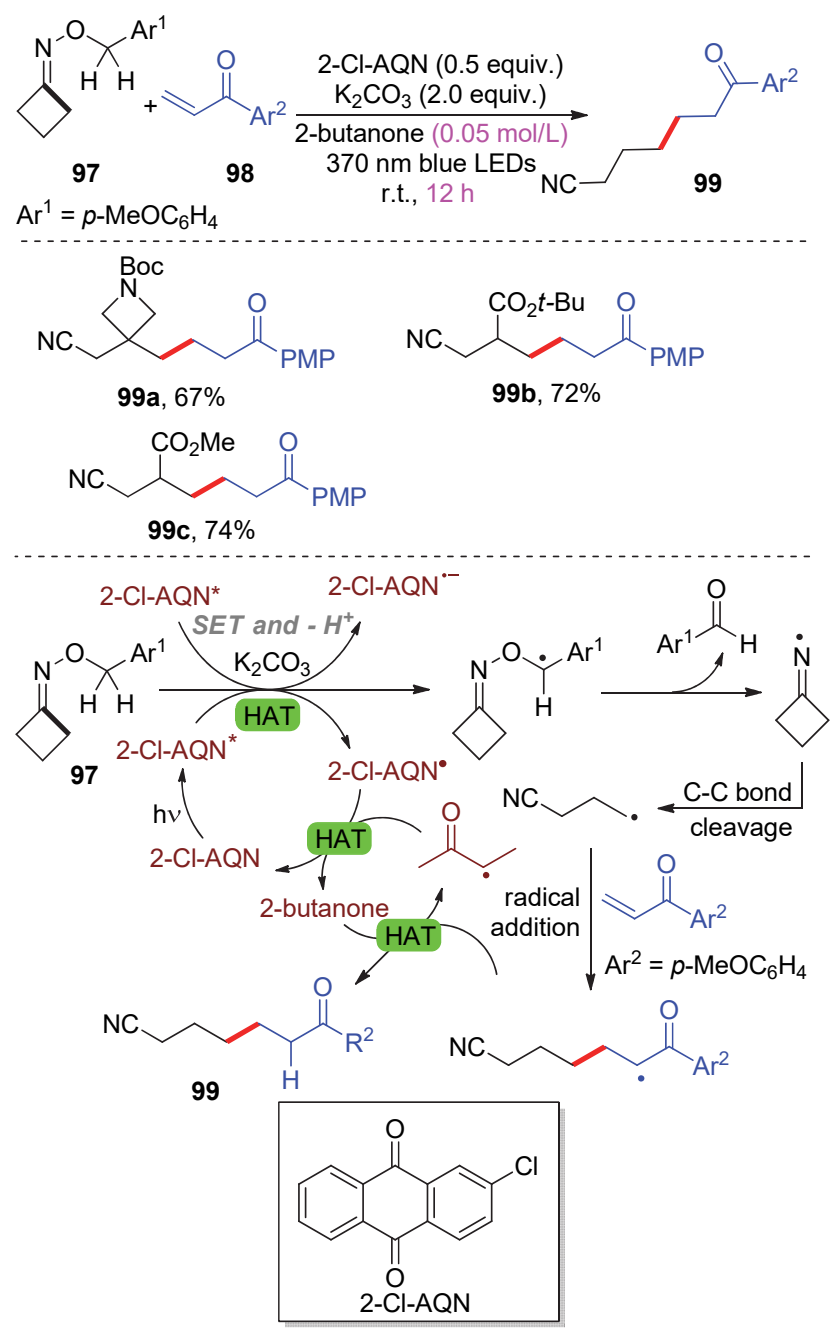

图式 $18 O$-苄基环丁酮肜醚的开环烷基化反应

Scheme 18 Ring-opening and alkylation of $O$-benzyl cyclobutanone oxime ether

肖文精和陈加荣等 ${ }^{[39]}$ 最近报道了一系列可见光促 进的铜催化的环酮肟酯参与的多组分反应, 比如环丁酮 肟酯 100/苯乙烯 101/芳基硼酸 102 (Scheme 19a)、环丁 酮肟酯 104/烯烃 105/末端炔 106 (Scheme 19b) ${ }^{[40]}$ 和环丁 酮肜酯 108/一氧化碳/苯胺 109 (Scheme 19c) ${ }^{[41]}$ 的三组分 自由基交叉偶合反应. 最近, 他们课题组又开发了一种 可见光驱动铜催化的环丁酮肜酯 112 与酚类或醇类 113 的 $\mathrm{C}\left(\mathrm{sp}^{3}\right)-\mathrm{O}$ 交叉偶联反应 ${ }^{[42]}$. 这一策略也适用于茮基
叠氮化、硫㲵化和硫醚化(Scheme 19d). 在这些反应中, 无需外加贵金属钉或者铱的配合物作为光敏剂，廉价金 属铜的配合物作为吸收光子的物种，扮演光敏剂的作 用，同时金属铜还参与化学键的断裂和形成，是一个双 功能催化剂(Scheme 19e). 该策略进一步拓展了亚胺自 由基参与的反应类型，提供了构建有价值的官能团丰富 的有机腈类化合物.

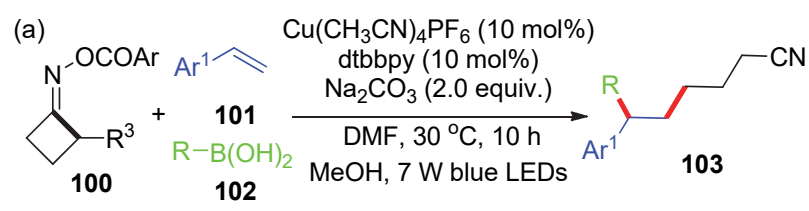

(b)
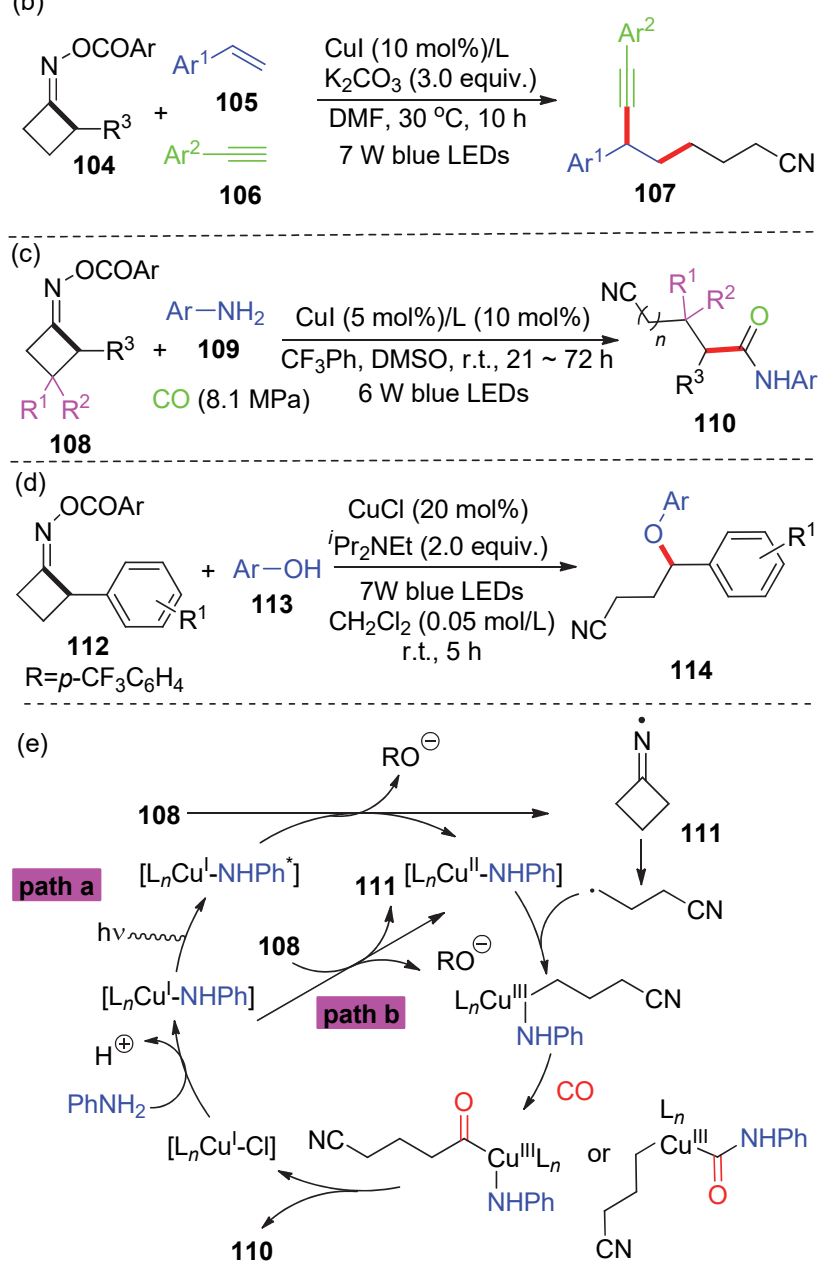

图式 19 可见光促进的铜催化环丁酮肜酯参与的反应

Scheme 19 Visible light-mediated and copper-catalyzed reactions of cyclobutanone oxime esters

为了进一步拓展光催化反应的适用范围，过渡金属 与光协同催化的反应模式受到了关注. 在这一反应模式 中，光催化剂可以与过渡金属发生能量或者电子转移， 过渡金属参与化学键的形成或者断裂. 这一反应模式大 大拓展了光催化反应的适用范围, 在亚胺自由基化学中 也可以得到应用. Leonori 等 ${ }^{[43]}$ 报道了使用可见光氧化 
还原与镍协同催化策略可以实现环酮肜羧酸衍生物开 环芳基化、烯基和烷基化反应(Scheme 20). 该策略采用 环丁酮肜羧酸衍生物 115 在可见光氧化还原催化下脱羧 和丙酮生成亚胺自由基, 开环形成的烷基自由基在镍催 化下实现芳基化(116)、烯基化(117)和烷基化(118).

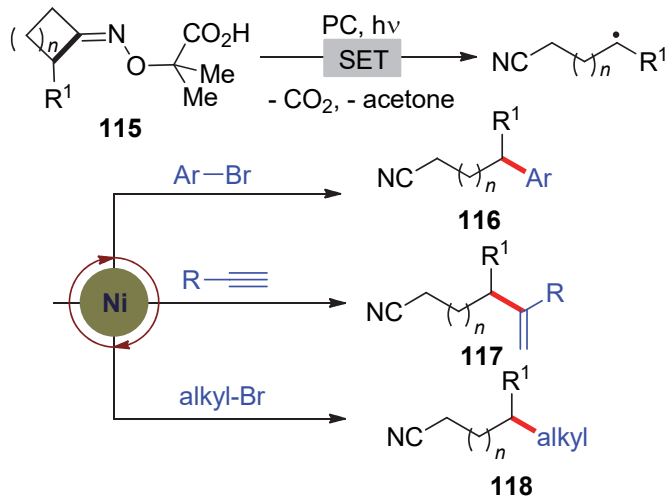

图式 20 可见光促进的镍催化的芳基化、烯基以及烷基化反 应

Scheme 20 Visible light promoted Nickel catalyzed arylation, alkenyl and alkylation

肖文精和陈加荣等 ${ }^{[44]}$ 实现了光氧化还原与铜协同
催化环酮肟酯 119 的对映选择性的开环氰基化反应 (Scheme 21a). 该策略展示了广泛的底物范围，可以制 备各种具有光学活性的烷基二腈，具有高收率和优良的 对映体选择性. 几乎同时, 王细胜等 ${ }^{[45]}$ 报道了四元和五 元环酮肟酯 122 的自由基介导的开环和对映选择性氰基 化反应(Scheme 21b). 该策略可通过铜催化或者光氧化 还原与铜协同催化两种反应条件分别构建 1,5-和 1,6-二 氧手性化合物. 这两个工作是为数不多的亚胺自由基参 与的对映选择性反应.

除了环酮肟酯的开环反应外，亚胺基自由基还可以 经历非环状底物的 Norrish-I型断裂反应. 杨尚东 ${ }^{[46]}$ 与吴 骊珠等 ${ }^{[47]}$ 发现由 $O$-酰基肟衍生物产生的亚胺自由基可 以发生 Norrish-I 型断裂反应，分别产生膦中心自由基碳 中心自由基，同时释放小分子腈类化合物. 膦中心自由 基或酰基自由基可以被苯乙烯衍生物捕获，得到的茮位 再经历氧化、Ritter/Mumm 重排反应或与胺以及羧酸的 亲核环化生成 $\beta$-氨基膦酸酯 127, 131, 132 (Schemes $22 \mathrm{a}$, $22 b$ )或 $\beta$-氨基酰基化产物 135, 138, 139 (Schemes 22c, 22d). Ritter/Mumm 重排反应序列在氮自由基启动的烯

(a) Xiao and Chen's work

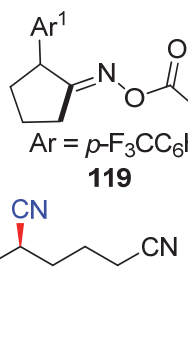

121a, $R=H, 92 \%, 91 \%$ ee 121b, $R=$ TMS, $99 \%, 91 \%$ ee

121c, $\mathrm{R}=\mathrm{CO}_{2} \mathrm{Me}, 94 \%, 94 \%$ ee
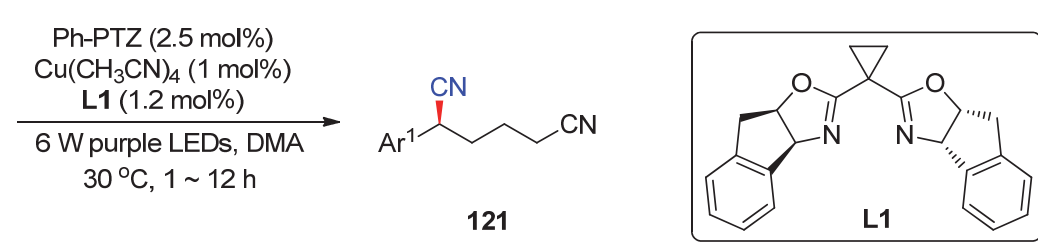

121

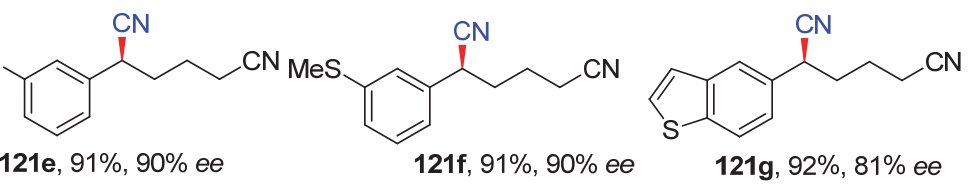

121e, $91 \%, 90 \%$ ee 121f, $91 \%, 90 \%$ ee

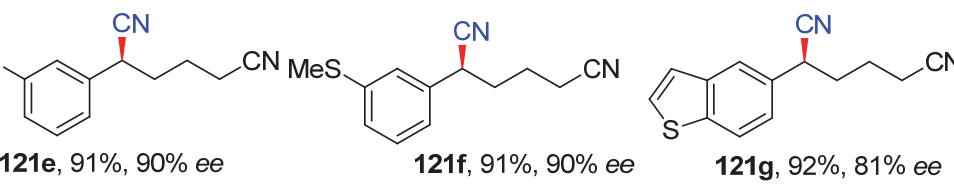

121g, $92 \%, 81 \%$ ee (b) Wang's work<smiles>[R]C(=O)O/N=C1\[Y20](=[Pt])CC1Br</smiles>

124a, $73 \%, 94 \%$ ee

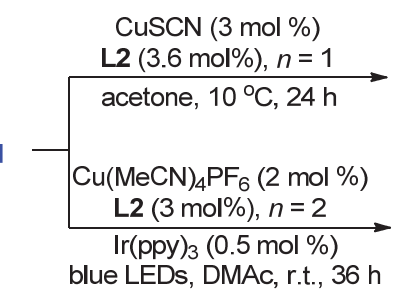<smiles>CC(Br)CCCC#N</smiles>

124

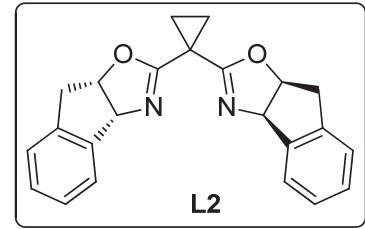<smiles>N#CCCC(C#N)c1ccc(Br)cc1</smiles>

124d, $89 \%, 94 \%$ ee<smiles>N#CCCCC(C#N)c1ccc(-c2ccccc2)cc1</smiles><smiles>N#CCCC[C@H](C#N)c1ccc2ccccc2c1</smiles>

124b, $79 \%$, 90\% ee<smiles>N#CCC[C@H](C#N)c1ccc(Oc2ccccc2)cc1</smiles>

124c, $82 \%, 91 \%$ ee<smiles>[14CH3]c1cc(C(C#N)CCCC#N)cc2ccsc12</smiles>

图式 21 光氧化还原和铜协同催化不对称远程氰化反应

Scheme 21 Dual photoredox and copper catalyzed asymmetric remote cyanation reaction 
烃加成反应中也同样被观察到 ${ }^{[48]}$. 烷基自由基经历氧 化后，直接接受亲核试剂(醇或胺)的进攻，生成醚类 143 或胺类产物 144 (Scheme 22e). 该方法的特点是能够在 不需要氧化剂和碱的情况下构建 $C\left(\mathrm{sp}^{3}\right)-\mathrm{P}$ 和 $\mathrm{C}\left(\mathrm{sp}^{3}\right)-\mathrm{N}$ 以及 $\mathrm{C}\left(\mathrm{sp}^{3}\right)-\mathrm{O}$ 键 (Scheme 22).

\section{5 总结和展望}

亚胺自由基为中间体参与的反应是构建羰基以及 含氮化合物的重要方法. 可见光还原氧化催化反应具有 环境友好、温和的反应条件以及操作简单等优点, 其原 理是通过激发态的光敏剂与底物实现单电子转移生成
自由基或自由基离子中间体，进而实现下一步的转化. 本文详细总结了光氧化还原催化条件下以肜的衍生物 作为前体，亚胺自由基的产生及其参与的反应，主要包 括对芳烃的加成反应、分子内的氢迁移、对烯烃的加成 反应以及 Norrish-I 型断裂反应等. 在光氧化还原催化条 件下亚胺自由基的产生方便高效，其参与的反应类型也 较为丰富. 但鉴于亚胺自由基的高活性，其参与反应的 立体选择性通常较差, 对映选择性的反应极少报道. 亚 胺自由基参与的反应立体选择性(包括非对映选择性和 对映选择性)控制是该领域亟需解决的问题，也是未来 重要的研究方向.

(a) Yang's work<smiles>[R]OC(=O)O/N=C(/[Y17])[OH2+]</smiles>

125

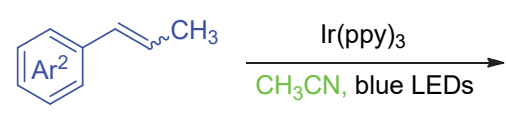

126<smiles>[R]C(=O)N(C(C)=O)C(c1ccccc1)C(C)POCC</smiles>

127

(b)<smiles>CCOC(=O)N=C(C(=O)OCC)c1ccccc1</smiles><smiles>C=C(CNCCN)c1ccccc1</smiles>

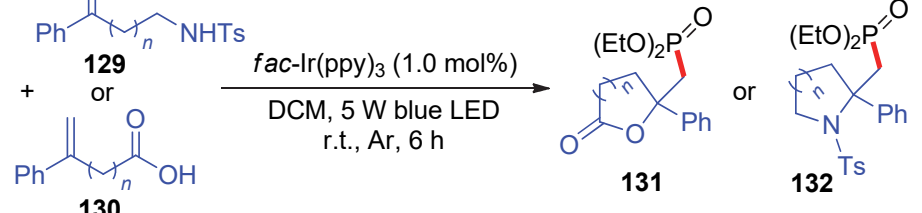
$132^{\text {Ts }}$

130

(c) Wu's work

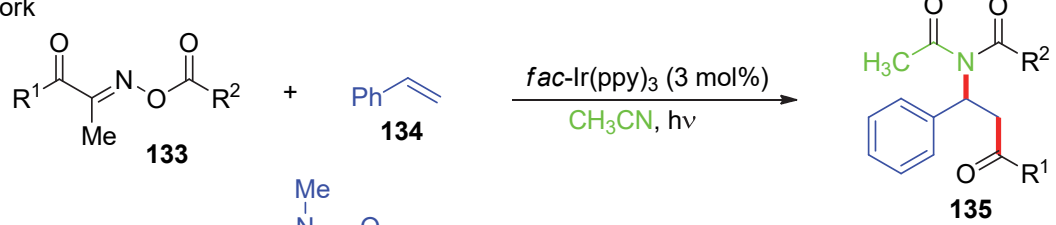

(d)

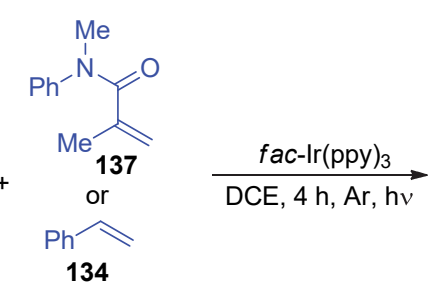
$\mathrm{R}^{1}=$ alkyl, aryl

(e)

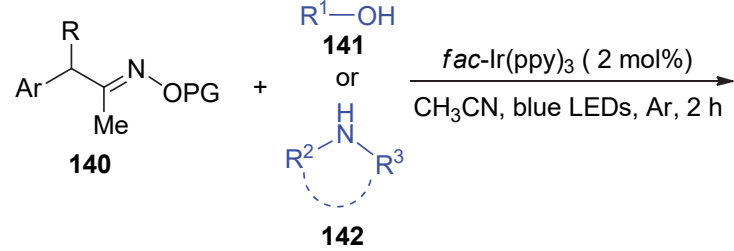<smiles>[R1]C(=O)CC1(C)C(=O)N(C)c2ccccc21</smiles><smiles>[R]C(=O)C1CC([Al])C1[Te]</smiles>

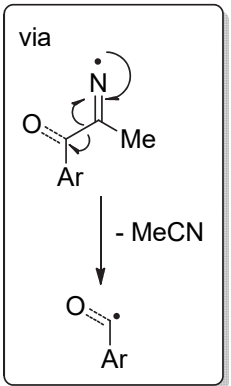

图式 22 可见光促进的非环状底物的 Norrish-I 型断裂反应

Scheme 22 Visible light-promoted Norrish-I fracture reaction of non-cyclic substrates

\section{References}

[1] Lawrence, S. A. Amines: Synthesis Properties and Applications, Cambridge University, Cambridge, 2005, p. 1016.

[2] Zard, S. Z. Chem. Soc. Rev. 2008, 37, 1603.

[3] (a) Prier, C. K.; Rankic, D. A.; MacMillan, D. W. C. Chem. Rev. 2013, 113, 5322 .

(b) Skubi, K. L.; Blum, T. R.; Yoon, T. P. Chem. Rev. 2016, 116, 10035 . (c) Romero, N. A.; Nicewicz, D. A. Chem. Rev. 2016, 116, 10075. (d) Chen, Y.; Lu, L.-Q; Yu, D.-G; Zhu, C.-J; Xiao, W.-J. Sci. China Chem. 2019, 62, 24.

(e) Chen, F.; Chen, H.; Wu, Q.-A.; Luo, S.-P. Chin. J. Org. Chem. 2020, 40, 339 (in Chinese).

(陈锋, 陈浩, 吴庆安, 罗书平, 有机化学, 2020, 40, 339.)

[4] (a) Davies, J.; Morcillo, S. P.; Douglas, J. J.; Leonori, D. Chem. Eur. J. 2018, 24, 12154.

(b) Kärkäs, M. D. ACS Catal. 2017, 7, 4999. 
(c) An, X.-D.; Yu, S. Tetrahedron Lett. 2018, 59, 1605.

(d) Jackman, M. M.; Cai, Y.; Castle, S. L. Synthesis 2017, 49, 1785.

(e) Chen, J.-R.; Hu, X.-Q.; Lu, L.-Q.; Xiao, W.-J. Chem. Soc. Rev. 2016, 45, 2044.

(f) Xiao, L; Li, J.-H; Wang, T. Acta Chim. Sinica 2019, 77, 841 (in Chinese).

(肖丽, 李嘉恒, 王挺, 化学学报, 2019, 77, 841.)

(g) Xu, X.-L.; Wan, X.; Geng, Y.; Zhang, J.-S.; Xu, H.-J. Chin. J. Org. Chem. 2011, 31, 453 (in Chinese).

(徐小岗, 万薪, 耿烨, 张家松, 许华建, 有机化学, 2011, 31, 453).

(h) Xiong, T.; Zhang, Q. Chem. Soc. Rev. 2016, 45, 3069.

(i) Song, H.; Liu, X.-Y.; Qin, Y. Acta Chim. Sinica 2017, 75, 1137 (in Chinese).

(宋影, 刘小宇, 秦勇, 化学学报, 2017, 75, 1137.)

(j) Yu, X.-Y.; Zhao, Q.-Q.; Chen, J.; Xiao, W.-J.; Chen, J.-R. Acc. Chem. Res. 2020, Acc. Chem. Res. 2020, 53, 1066.

[5] Walton, J. C. Acc. Chem. Res. 2014, 47, 1406.

[6] Luo, Y.-R. Handbook of Bond Dissociation Energies in Organic Compounds, CRC, Boca Raton, 2003, p. 392.

[7] Jiang, H.; An, X. D.; Tong, K.; Zheng, T.; Zhang, Y.; Yu, S. Angew. Chem., Int. Ed. 2015, 54, 4055.

[8] An, X.-D.; Yu, S. Org. Lett. 2015, 17, 2692.

[9] Sun, J.-J; He, Y.-Y; An, X.-D; Zhang, X; Yu, L; Yu, S. Org. Chem. Front. 2018, 5, 977.

[10] Liu, X.-B.; Qing, Z.-X.; Zheng, X.-Y.; Zeng, J.-G.; Cheng, P.; Xie, H.-Q. Molecules 2016, 21, 1690.

[11] Matsushita, Y.; Ochi, R. Tanaka, Y.; Koike, T.; Akita, M. Org. Chem. Front. 2020, 7, 1243.

[12] (a) Qin, Q.-X; Yu, S. Org. Lett. 2015, 17, 1894. (b) Shen, X.; Zhao, J.-J.; Yu, S. Org. Lett. 2018, 20, 5523.

[13] Shu, W.; Nevado, C. Angew. Chem., Int. Ed. 2017, 56, 1881.

[14] Ma, Z.-Y.; Guo, L.-N.; Gu, Y.-R.; Chen, L.; Duan, X.-H. Adv. Synth. Catal. 2018, 360, 4341.

[15] Chen, L; Guo, L.-N.; Ma, Z.-Y.; Gu, Y.-R.; Zhang, J.; Duan, X.-H. J. Org. Chem. 2019, 84, 6475.

[16] Dauncey, E. M.; Morcillo, S. P.; Douglas, J. J.; Sheikh, N. S.; Leonori, D. Angew. Chem., Int. Ed. 2018, 57, 744.

[17] Jiang, H.; Studer, A. Angew. Chem., Int. Ed. 2018, 57, 1692.

[18] Li, J.-J.; Zhang, P.-P.; Jiang, M.; Yang, H.-J.; Zhao, Y.-F.; Fu, H. Org. Lett. 2017, 19, 1994.

[19] Li, Y.-W.; Mao, R.-Y.; Wu, J. Org. Lett. 2017, 19, 4472.

[20] Tadic-Biadatti, M.-H. L.; Callier-Dublanchet, A.; Horner, J. H.; Quiclet-Sire, B.; Zard, S. Z.; Newcomb, M. J. Org. Chem. 1997, 62, 559.

[21] Boivin, J; Schiano, A.-M; Zard, S. Z; Zhang, H.-W. Tetrahedron Lett. 1999, 40, 4531 .

[22] Mikami, T.; Narasaka, K. Chem. Lett. 1999, 24, 338.

[23] Davies, J.; Booth, S. G.; Essafi, S.; Dryfe, Robert A. W.; Leonori, D. Angew. Chem., Int. Ed. 2015, 54, 14017.

[24] Cai, S.-H.; Xie, J.-H; Song, S.-J.; Ye, L.; Feng, C.; Loh, T. P. ACS Catal. 2016, 6, 5571.

[25] Jiang, H.; Studer, A. Angew. Chem., Int. Ed. 2017, 56, 12273.
[26] Davies, J.; Sheikh, N. S.; Leonori, D. Angew. Chem., Int. Ed. 2017, $56,13361$.

[27] (a) Yin, W.; Wang, X. New J. Chem. 2019, 43, 3254.

(b) Xiao, T.-B.; Huang, H.-T.; Anand, D.; Zhou, L. Synthesis 2020, Synthesis 2020, 52, 1585 .

[28] Boivin, J.; Fouquet, E.; Zard, S. Z. Tetrahedron 1994, 50, 1757.

[29] Yu, X.-Y.; Chen, J.-R.; Wang, P.-Z.; Yang, M.-N.; Liang, D.; Xiao, W.-J. Angew. Chem., Int. Ed. 2018, 57, 738

[30] He, B.-Q.; Yu, X.-Y.; Wang, P.-Z.; Chen, J.-R.; Xiao, W.-J. Chem. Commun. 2018, 54, 12262.

[31] Wang, P.-Z.; Yu, X.-Y.; Li, C.-Y.; He, B.-Q.; Chen, J.-R.; Xiao, W.-J. Chem. Commun. 2018, 54, 9925.

[32] Li, L.; Chen, H.; Mei, M.; Zhou, L. Chem. Commun. 2017, 53, 11544.

[33] Vaillant, F. L.; Garreau, M.; Nicolai, S.; Grynova, G.; Corminboeuf, C.; Waster, J. Chem. Sci. 2018, 9, 5883.

[34] Zhang, J.; Li, X.-F.; Xie, W.-L.; Ye, S.-Q.; Wu, J. Org. Lett. 2019, $21,4950$.

[35] Zheng, M.; Li, G.-L.; Lu, H.-J. Org. Lett. 2019, 21, 1216.

[36] Liu, Y.; Wang, Q.-L.; Chen, Z.; Li, H.; Xiong, B.-Q.; Zhang, P.-L.; Tang, K.-W. Chem. Commun. 2020, 56, 3011.

[37] Jian, Y.; Chen, M.; Yang, Chao; Xia, W.-J. Eur. J. Org. Chem. 2020, 1439.

[38] Wang, P.-Z.; He, B.-Q.; Cheng, Y.; Chen, J.-R.; Xiao, W.-J. Org. Lett. 2019, 21, 6924.

[39] Yu, X.-Y.; Zhao, Q.-Q.; Chen, J.; Chen, J.-R.; Xiao, W.-J. Angew. Chem., Int. Ed. 2018, 57, 15505.

[40] Chen, J.; He, B-Q.; Wang, P.-Z.; Yu, X.-Y.; Zhao, Q.-Q.; Chen, J.-R.; Xiao, W.-J. Org. Lett. 2019, 21, 4359.

[41] Lu, B.; Cheng, Y.; Chen, L.-Y.; Chen, J. R.; Xiao, W.-J. ACS Catal. 2019, $9,8159$.

[42] Yu, X.-Y.; Chen, J.; Chen, H.-W.; Xiao, W.-J.; Chen, J.-R. Org. Lett. 2020, 22, 2333.

[43] Dauncey, E. M.; Dighe, S. U.; Douglas, J. J.; Leonori, D. Chem. Sci. 2019, 10, 7728.

[44] Chen, J.; Wang, P.-Z.; Lu, B.; Liang, D.; Yu, X.-Y.; Xiao, W.-J.; Chen, J. R. Org. Lett. 2019, 21, 9763.

[45] Wang, T.; Wang; Y.-N.; Wang, R.; Zhang, B.-C.; Yang, C.; Li, Y.-L.; Wang, X.-S. Nat. Commun. 2019, 10, 5373.

[46] (a) Li, Y.-H.; Wang, C.-H.; Gao, S.-Q.; Qi, F.-M.; Yang, S.-D. Chem. Commun. 2019, 55, 11888.

(b) Li, C.; Qi, Z.-C.; Yang, Q.; Qiang, X.-Y.; Yang, A.-D. Chin. J. Chem. 2018, 36, 1052.

[47] (a) Cheng, Y.-Y.; Lei, T.; Su, L.-L.; Fan, X.-W.; Chen, B.; Tung, C.-H.; Wu, L.-Z. Org. Lett. 2019, 21, 8789.

(b) Fan, X.-W.; Lei, T.; Chen, B.; Tung, C.-H.; Wu, L.-Z. Org. Lett. 2019, 21, 4153.

(c) Fan, X.-W.; Lei, T.; Liu, Z.; Yang, X.-L.; Cheng, Y.-Y.; Liang, G.; Chen, B.; Tung, C.-H.; Wu, L.-Z. Eur. J. Org. Chem. 2020, 10, 1551.

[48] Qin, Q.; Han, Y.-Y; Jiao, Y.-Y; He, Y.; Yu, S. Org. Lett. 2017, 19, 2909. 